
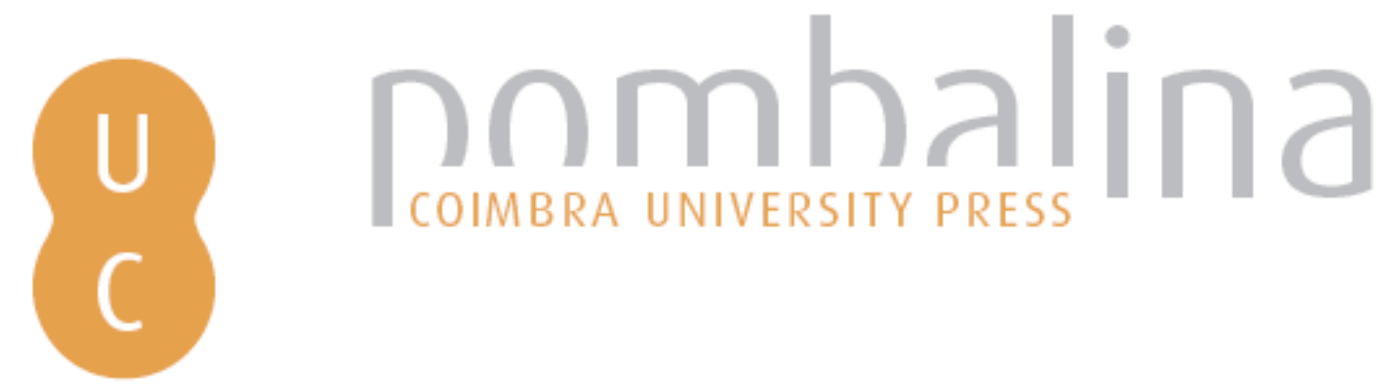

\title{
Construção de modelos de avaliação de vulnerabilidade social a riscos naturais e tecnológicos: o desafio das escalas
} \author{
$\begin{array}{ll}\text { Autor(es): } & \text { Cunha, Lúcio; Mendes, José Manuel; Tavares, Alexandre; Freiria, } \\ \text { Susana }\end{array}$
}

Publicado por: Imprensa da Universidade de Coimbra

URL persistente:

URI:http://hdl.handle.net/10316.2/31159

DOI:

DOI:http://dx.doi.org/10.14195/978-989-26-0244-8_71

Accessed : $\quad$ 26-Apr-2023 15:28:42

A navegação consulta e descarregamento dos títulos inseridos nas Bibliotecas Digitais UC Digitalis, UC Pombalina e UC Impactum, pressupõem a aceitação plena e sem reservas dos Termos e Condições de Uso destas Bibliotecas Digitais, disponíveis em https://digitalis.uc.pt/pt-pt/termos.

Conforme exposto nos referidos Termos e Condições de Uso, o descarregamento de títulos de acesso restrito requer uma licença válida de autorização devendo o utilizador aceder ao(s) documento(s) a partir de um endereço de IP da instituição detentora da supramencionada licença.

Ao utilizador é apenas permitido o descarregamento para uso pessoal, pelo que o emprego do(s) título(s) descarregado(s) para outro fim, designadamente comercial, carece de autorização do respetivo autor ou editor da obra.

Na medida em que todas as obras da UC Digitalis se encontram protegidas pelo Código do Direito de Autor e Direitos Conexos e demais legislação aplicável, toda a cópia, parcial ou total, deste documento, nos casos em que é legalmente admitida, deverá conter ou fazer-se acompanhar por este aviso.

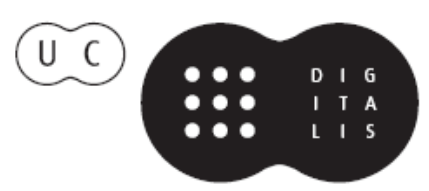




\section{TRUNFOS DE UMA}

\section{EOGRAFIA ACIVA}

\section{DESENVOLVIMENTO LOCAL,}

AMBIENTE,

ORDENAMENTO

E TECNOLOGIA

Norberto Santos

Lúcio Cunha

COORDENAÇÃO 
Lúcio Cunha ${ }^{1}$, José Manuel Mendes ${ }^{2}$, Alexandre Tavares ${ }^{3}$, Susana Freiria ${ }^{2}$

${ }^{1}$ Departamento de Geografia da Faculdade de Letras da Universidade de Coimbra

${ }^{2}$ Centro de Estudos Sociais, Faculdade de Economia da Universidade de Coimbra

${ }^{3}$ Centro de Estudos Sociais, Faculdade de Ciências e Tecnologia da Universidade de Coimbra

\section{CONSTRUÇÃO DE MODELOS DE AVALIAÇÃO DE VULNERABILIDADE SOCIAL A RISCOS NATURAIS E TECNOLÓGICOS. O DESAFIO DAS ESCALAS}

\section{INTRODUÇÃO}

Quer em termos conceptuais, quer, sobretudo, em termos operacionais e, particularmente, no que diz respeito à sua cartografia, os riscos, sejam eles naturais, tecnológicos ou mistos, definem-se na articulação da chamada perigosidade ${ }^{1}$ com a vulnerabilidade. Como se correspondessem às duas faces da mesma moeda, de um lado estáo os processos perigosos, do outro a sociedade, a economia e a cultura por eles potencialmente afectados.

De entre os muitos trabalhos desenvolvidos no nosso país sobre a temática dos riscos, parece haver uma maior propensão para o estudo dos processos perigosos do que para o estudo do modo como a sociedade os recebe, lhes resiste ou deles recupera. Dito doutro modo, em termos de ciência do risco, as vertentes susceptibilidade e perigosidade continuam a ser bem mais estudadas que a vertente vulnerabilidade.

Segundo a UN-ISDR (2009) o termo vulnerabilidade refere-se à propensão da população exposta ou dos recursos económicos sofrerem perdas na dependência das suas características físicas, sociais, políticas, económicas, culturais e institucionais. Corresponde assim, a um conceito complexo que envolve, por um lado, a exposição de pessoas e bens e, por outro, o nível de resistência e de resiliência de indivíduos e comunidades quando expostos a processos e eventos potencialmente prejudiciais, ou seja a chamada vulnerabilidade social, objecto fundamental deste texto. Nele aceitamos a acepção de Wisner et al. (2004) ou Hufschimdt et al. (2005) que consideram que a vulnerabilidade social representa o nível de resiliência e resistência dos indivíduos e comunidades, quando expostas a processos ou eventos perigosos (Mendes et al., 2009).

Com base nos trabalhos de Ribeiro (1995), Cutter et al. (2003); ONU (2004), Davis (2004); Schmidtlein et al. (2008) e na linha de outros trabalhos desenvolvidos no âmbito de um projecto de investigação em curso $^{2}$ (Mendes, 2009; Mendes e Tavares, 2008;

\footnotetext{
${ }^{1}$ Apesar de sabermos que não é absolutamente pacífica entre a comunidade de geógrafos portugueses a utilização do termo "perigosidade" como equivalente dos termos hazard (em inglês) ou aléa (em francês), optamos por ele neste trabalho, na falta de outro termo que, na língua portuguesa, melhor signifique a combinaçáo da susceptibilidade espacial e da probabilidade temporal de ocorrência de processos ou acçóes com potencial para provocar danos.

${ }^{2}$ Este trabalho foi desenvolvido no âmbito do Projecto "Risco, vulnerabilidade social e estratégias de planeamento: uma abordagem integrada" (PTDC/SDEI 72111/2006 - Sociologia e Demografia).
} 
Mendes et al., 2009), apresentamos uma proposta metodológica para a construção de um índice de vulnerabilidade social que integra, por um lado, a criticidade e, por outro, a capacidade de suporte do sistema territorial, às escalas nacional e municipal.

Tanto a nível global como a nível nacional, são inúmeros os casos recentes de acontecimentos naturais ou tecnológicos extremos que revelam a importância da vulnerabilidade e, mais especificamente, da vulnerabilidade social a que indivíduos, famílias e comunidades estão sujeitos, justificando este tipo de estudos e, particularmente, a importância da cartografia da vulnerabilidade social nas políticas de Gestáo de Risco e de Ordenamento do Território. Sirvam de exemplo, para já, alguns casos registados neste ano de 2010, quer no estrangeiro, como as inundaçóes e os movimentos em vertentes, no Brasil, ou dos sismos ocorridos no Haiti ou na China, quer entre nós, como a aluvião da Madeira de Fevereiro, os incêndios florestais e as ondas de calor do último Verão, em que, de facto, muito para além dos processos perigosos, ressalta a importância da vulnerabilidade e, dentro desta, para além da exposição das pessoas e do valor dos bens potencialmente afectados, da vulnerabilidade social.

\section{OBJECTIVOS E METODOLOGIA}

Neste estudo apresentamos uma avaliação prévia da vulnerabilidade social a nível do Continente, com desagregação dos valores a nível municipal, e a nível municipal, para sete concelhos seleccionados na Região Centro, com desagregaçáo dos valores a nível da freguesia.

Os pressupostos teóricos deste trabalho, nomeadamente no que se refere ao significado e importância da criticidade, que tem a ver com as características demográficas e comportamentais das populaçóes, e da capacidade de suporte, que tem em conta as infra-estruturas e recursos territoriais postos à sua disposiçáo, e ao significado dos diferentes elementos em função da escala de análise, estão já apresentados em anteriores trabalhos do grupo de investigação, nomeadamente em Mendes et al. (2009). Nesse trabalho encontra-se também explicitada a metodologia utilizada, pelo que nos limitaremos a apresentá-la aqui em breve síntese.

Figura 1 - Método de combinação dos valores de criticidade com a capacidade de suporte para determinação da vulnerabilidade social.

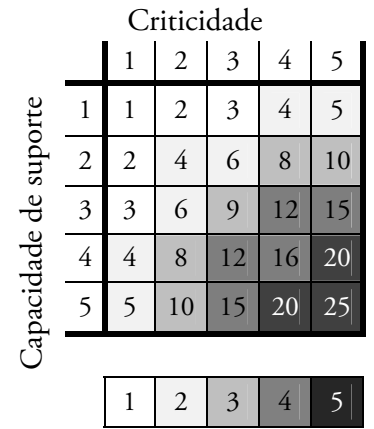

Classes de vulnerabilidade social (1 - Muito baixa; 5 - Muito elevada) 
Fundamentalmente, a análise da criticidade e da capacidade de suporte baseia-se numa análise factorial de componentes principais (ACP) de um conjunto de variáveis, organizadas segundo as seguintes categorias: demografia, edifícios, economia, educação, justiça, saúde, habitação, protecção civil, apoio social e investimento ambiental. Os resultados finais para os valores da criticidade e da capacidade de suporte foram obtidos através do cruzamento dos scores de cada unidade territorial, ponderados através do peso explicativo de cada um dos factores. Para efeitos cartográficos os resultados da criticidade e da capacidade de suporte foram classificados em cinco categorias (de muito baixa a muito elevada, no caso da criticidade, e de muito elevada a muito baixa, no caso da capacidade de suporte). Os mapas de vulnerabilidade social, também classificados em cinco categorias resultam do cruzamento simples entre os dois mapas anteriores, de acordo com a tabela da fig. 1.

\section{RESULTADOS}

Análise da criticidade e da capacidade de suporte à escala nacional

A avaliação dos níveis de criticidade baseou-se em 96 variáveis, as quais foram reduzidas a 56, após uma análise da multicolinearidade, e a 22, após a análise factorial (Tabela 1). Com base nestas 22 variáveis explicativas foram retidos 6 factores, que explicam $76 \%$ da variância entre todos os municípios de Portugal.

Tabela 1 - Número de variáveis na avaliação da criticidade à escala nacional

\begin{tabular}{|l|ccc|}
\hline \multirow{2}{*}{ Grupos } & \multicolumn{3}{c|}{ Variáveis } \\
\cline { 2 - 4 } & Iniciais & Modelo & Explicativas \\
\hline Apoio Social & 23 & 16 & 2 \\
Condiçáo dos edificios & 11 & 9 & 3 \\
Demografia & 11 & 7 & 2 \\
Economia & 26 & 13 & 9 \\
Educaçáo & 8 & 3 & 2 \\
Habitaçãa & 11 & 8 & 4 \\
Justiça & 6 & 0 & 0 \\
\hline Total & 96 & 56 & 22 \\
\hline
\end{tabular}

Tabela 2 - Factores retidos e significância explicada para avaliação da criticidade

\begin{tabular}{|c|c|c|c|c|}
\hline Factores & Designação & $\begin{array}{c}\text { Variância } \\
\text { explicada }(\%)\end{array}$ & Variável dominante & $\begin{array}{c}\text { Correlaçáo (var. } \\
\text { dominante/factor) }\end{array}$ \\
\hline 1 & $\begin{array}{l}\text { Estrutura } \\
\text { demográfica }\end{array}$ & 29 & $\begin{array}{l}\text { Indivíduos empregados em actividades } \\
\text { relacionadas com a pesca e a agricultura (\%) }\end{array}$ & $-0,86$ \\
\hline 2 & $\begin{array}{l}\text { Poder } \\
\text { económico }\end{array}$ & 19 & $\begin{array}{l}\text { Depósitos de clientes em outro } \\
\text { estabelecimento intermédio por habitante }\end{array}$ & 0,84 \\
\hline 3 & $\begin{array}{l}\text { Parque } \\
\text { habitacional }\end{array}$ & 10 & Índice de envelhecimento dos edificios & 0,77 \\
\hline 4 & $\begin{array}{l}\text { Estrutura } \\
\text { sócio- } \\
\text { profissional }\end{array}$ & 7 & $\begin{array}{l}\text { Indivíduos empregados em actividades } \\
\text { relacionadas com o comércio (\%) }\end{array}$ & 0,83 \\
\hline 5 & $\begin{array}{l}\text { Beneficiários } \\
\text { do RMG }\end{array}$ & 6 & Beneficiários do RMG (\%) & 0,88 \\
\hline 6 & $\begin{array}{l}\text { Dinamismo } \\
\text { económico }\end{array}$ & 5 & $\begin{array}{l}\text { Actos notariais celebrados por escritura - } \\
\text { compra e venda de imóveis (\%) }\end{array}$ & 0,87 \\
\hline
\end{tabular}


A figura 2 mostra a posição dos diferentes municípios face aos dois principais factores. Realça-se a maior homogeneidade dos valores relativos ao factor 1 (estrutura demográfica) por relação ao factor 2 (poder económico). Salientam-se, também, muito claramente algumas diferenças significativas no nosso país, nomeadamente as oposiçóes entre os municípios de Moita e Melgaço, no que diz respeito à estrutura demográfica, com o primeiro município a apresentar um posição mais favorável (população menos envelhecida, p. ex.) e entre Lisboa e Barrancos, no que se refere ao poder económico.

Figura 2 - Criticidade em Portugal Continental. Posição dos municípios em relação aos factores 1 (Estrutura demográfica) e 2 (poder económico)

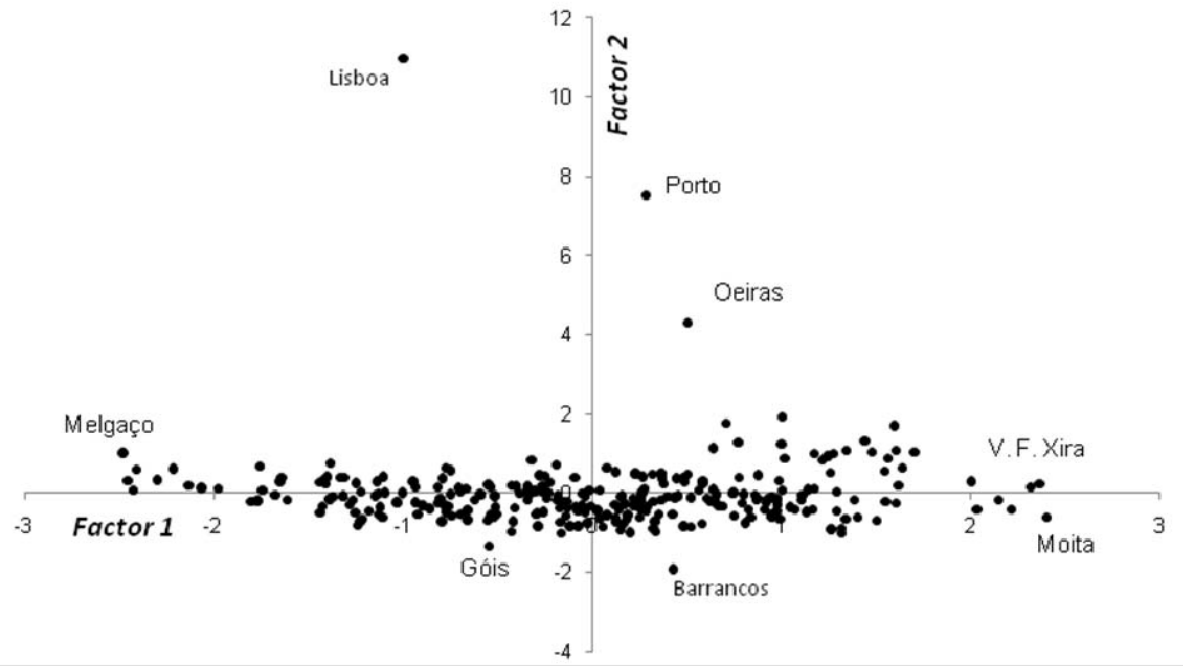

No que diz respeito à capacidade de suporte à escala nacional, das 145 variáveis iniciais apenas 65 foram incluídas no modelo de ACP e, destas, 10 são suficientes para o explicar (Tabela 2).

Tabela 3 - Número de variáveis na avaliação da capacidade de suporte

\begin{tabular}{|l|ccc|}
\hline \multirow{2}{*}{ Grupos } & \multicolumn{3}{c|}{ Variáveis } \\
\cline { 2 - 4 } & Iniciais & Modelo & Explicativas \\
\hline Economia & 86 & 27 & 4 \\
Edificios & 11 & 9 & 0 \\
Habitação & 11 & 8 & 1 \\
Protecção Civil & 27 & 7 & 2 \\
Saúde & 10 & 10 & 3 \\
\hline Total & 145 & 61 & 10 \\
\hline
\end{tabular}

$\mathrm{Na}$ avaliação da capacidade de suporte à escala municipal foram retidos 4 factores que, no seu conjunto, explicam $71 \%$ da variância total (tabela 4). 
Tabela 4 - Factores retidos e significância explicada para avaliação da capacidade de suporte

\begin{tabular}{|c|l|c|l|c|}
\hline Factores & \multicolumn{1}{|c|}{ Designação } & $\begin{array}{c}\text { Variância } \\
\text { explicada (\%) }\end{array}$ & \multicolumn{1}{|c|}{ Variável dominante } & $\begin{array}{c}\text { Correlação var. } \\
\text { dominante/factor }\end{array}$ \\
\hline 1 & $\begin{array}{l}\text { Dinamismo económico e } \\
\text { ambiental }\end{array}$ & 31 & $\begin{array}{l}\text { N. }{ }^{\circ} \text { de caixas Multibanco } \\
\text { por } 1000 \text { habitantes }\end{array}$ & 0,87 \\
\hline 2 & $\begin{array}{l}\text { Corporaçóes de } \\
\text { bombeiros }\end{array}$ & 17 & $\begin{array}{l}\text { N. }{ }^{\circ} \text { de Corporaçôes de } \\
\text { bombeiros por cada } 10000 \\
\text { habitantes }\end{array}$ & 0,88 \\
\hline 3 & $\begin{array}{l}\text { Capacidade logística e } \\
\text { actividade seguradora }\end{array}$ & 12 & $\begin{array}{l}\text { Camas (lotação praticada) } \\
\text { por 1000 habitantes }\end{array}$ & 0,83 \\
\hline 4 & Farmácias & 10 & $\begin{array}{l}\text { Farmácias por } 10000 \\
\text { habitantes }\end{array}$ & 0,86 \\
\hline
\end{tabular}

O primeiro factor explica $31 \%$ da variância e reflecte o dinamismo económico e ambiental dos municípios. O segundo factor explica $17 \%$ da variância e está relacionado com o número de corpos de bombeiros por 10000 habitantes. A análise da posição que alguns municípios ocupam no cruzamento destes dois factores realça, no factor 1 , a oposição entre os municípios de Albufeira e Lisboa, que detêm uma posição mais favorável, e o de Cinfães, que revela uma menor capacidade económica e ambiental, bem como a posição fortemente positiva de pequenos municípios que, apesar da sua reduzida população, mantêm em funcionamento uma corporação de bombeiros (Barrancos, por exemplo).

Figura 3 - Capacidade de Suporte em Portugal Continental. Posição dos municípios em relação aos factores 1 (Dinamismo económico e ambiental) e 2 (Corporações de Bombeiros).

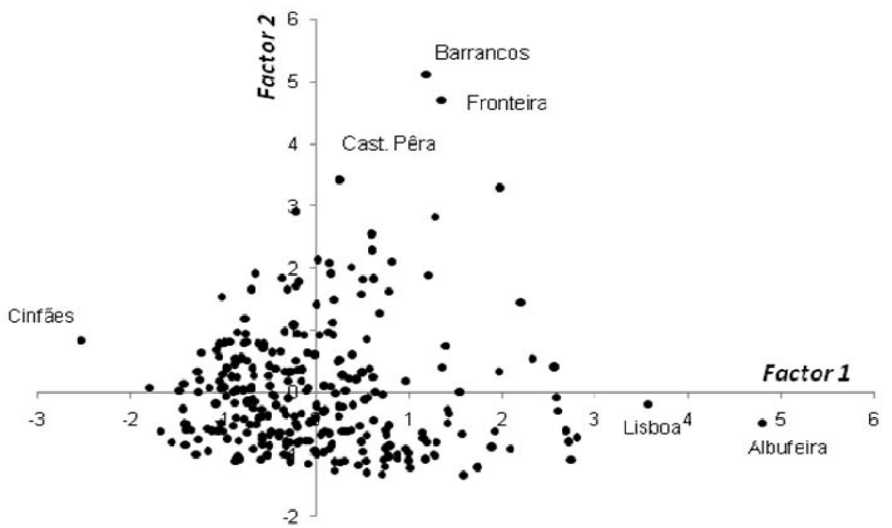

$\mathrm{Na}$ figura 4-A apresenta-se o mapa com os valores da criticidade, o qual reflecte muito claramente as anisotropias territoriais conhecidas para o país. Assim, os valores mais elevados correspondem essencialmente a municípios rurais do Norte do País (ex: Vinhais, Montalegre, Resende), em função, sobretudo, do forte envelhecimento da população e do muito baixo poder económico da população e dos municípios. Os valores elevados registam-se também nos municípios essencialmente rurais do interior (baixo poder económico, parque habitacional degradado, população envelhecida e estrutura profissional da população activa muito assente no sector primário). Os municípios das áreas metropolitanas de 
Lisboa e Porto, bem como os do sector litoral do Algarve, que concentram poder económico, oportunidades de trabalho e têm uma estrutura demográfica mais favorável apresentam, em regra, valores baixos de criticidade. O mesmo acontece com os municípios que, por serem sede de distrito reúnem as mesmas características mesmo quando se situam no Interior. Dos 18 municípios sede de distrito apenas o de Vila Real apresenta um valor médio de criticidade. Os restantes apresentam valores baixos ou mesmo muito baixos, acompanhando, assim, os municípios de Lisboa, Porto, Braga, Coimbra, Setúbal e Faro.

Figura 4 - Criticidade, capacidade de suporte e vulnerabilidade social em Portugal Continental
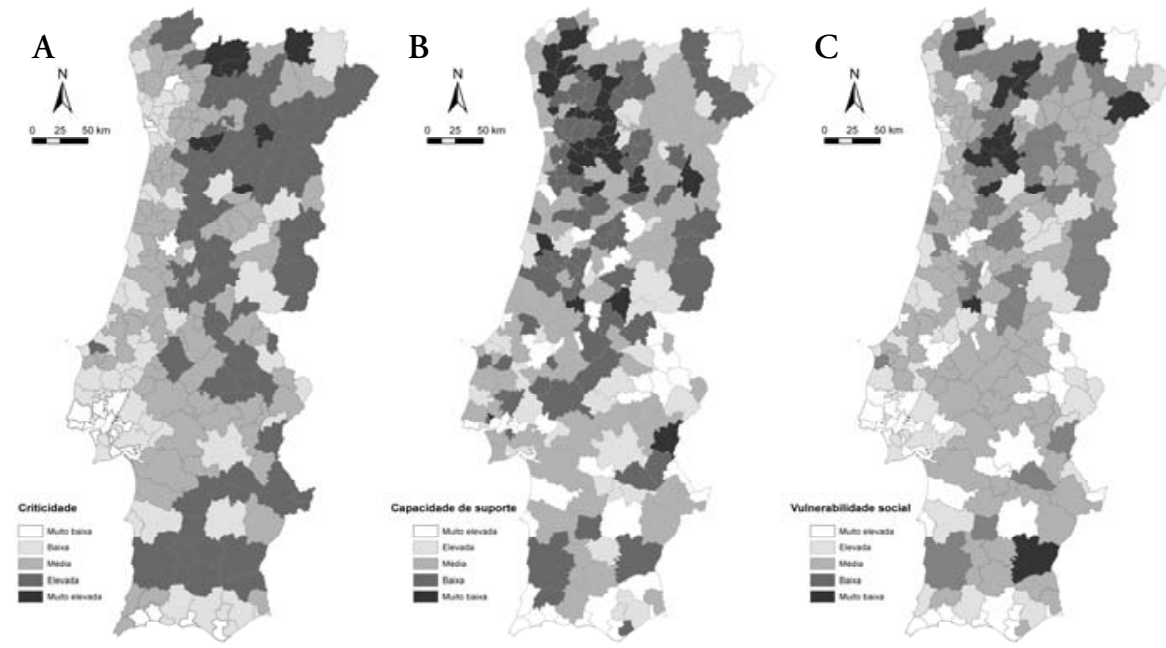

O mapa resultante da avaliação da capacidade de suporte à escala municipal é apresentado na figura 4-B. Os valores mais baixos em termos de capacidade de suporte evidenciam-se no Norte do país, nomeadamente nas sub-regiões do Tâmega, Cávado, Minho-Lima, Dão Latôes e Entre Douro e Vouga, em relação, sobretudo, com o seu fraco dinamismo económico. Os valores mais elevados encontram-se um pouco dispersos no Interior do país, na Regiáo do Algarve e nos municípios mais marcadamente urbanos de Lisboa e Porto. Enquanto muitos dos municípios encontram na relatividade de dotação infra-estrutural (Bombeiros; Farmácias) imposta pela baixa densidade demográfica a justificação para um valor elevado, no Algarve e nos municípios mais marcadamente urbanos é o dinamismo económico que impõe esse valor.

Análise da Vulnerabilidade Social à escala nacional

O cruzamento dos mapas de criticidade e de capacidade de suporte realizado através do método simples acima descrito, permite a leitura da vulnerabilidade social que se apresenta na fig. 4-C. Os municípios que apresentam mais elevada vulnerabilidade localizamse sobretudo no Norte do País e correspondem tanto àqueles que apresentam muito elevada criticidade (Vinhais, Boticas, Resende e Cinfães) como uma muito baixa capacidade de 
suporte (Arcos de Valdevez, Cabeceiras de Basto, Celorico de Basto, Baião, Cinfães, Arouca, Resende, Castro de Aire, Vouzela, Penalva do Castelo e Ferreira do Zêzere). Se bem que a leitura seja um tanto mais complicada que a dos mapas anteriores, pela maior complexidade de informação inserida nos modelos, resultam muito claras as principais assimetrias verificadas. Assim, também neste caso se distingue bem o Norte do Sul, o Litoral do Interior e particularmente, as áreas metropolitanas de Lisboa e Porto bem como o Algarve dos municípios predominantemente rurais. No Interior do país ressaltam quase sempre com níveis baixos e muito baixos de vulnerabilidade social os municípios urbanos que correspondem a sedes de distrito (muito baixos: Bragança, Portalegre, Évora e Beja; baixos: Vila Real, Viseu, Guarda, Castelo Branco), pela acumulação de poder económico e pelas infra-estruturas que acomodam.

Análise da criticidade e da capacidade de suporte à escala municipal

A fim de estudar o comportamento das duas componentes da fórmula de avaliação da vulnerabilidade social (criticidade e capacidade de suporte), bem como o impacto da variação de escala nos índices de vulnerabilidade, foram seleccionados sete municípios da Região Centro de Portugal (Ovar, Coimbra, Marinha Grande, Nelas, Almeida e Proença-a-Nova). Este grupo de municípios foi seleccionado com base num conjunto de critérios, entre os quais se contam a localização, a área geográfica do município, o número de habitantes, a densidade populacional, o número de freguesias, a área urbana e rural e a relevância das actividades industriais, agro-florestais e terciárias (Mendes et al., 2009).

A avaliaçáo da criticidade destes municípios, à escala da freguesia, foi feita com base em 79 variáveis. Nesta avaliaçáo foram retidos 3 factores que explicam $78 \%$ da variância (Mendes et al., ob. cit.)

No factor 1, que explica $40 \%$ da variância, a variável dominante é a taxa de desemprego, seguida por variáveis relacionadas com a estrutura demográfica. O factor 2, que explica $21 \%$ da variância, centra-se num grupo socialmente vulnerável: população portadora de deficiência vista através dos indivíduos com um grau de incapacidade superior a $80 \%$. O factor 3 , que explica $17 \%$ da variância, é constituído apenas pela percentagem de edificios construídos antes de 1960. Trata-se de um factor útil na identificação das áreas urbanas mais consolidadas.

No que diz respeito aos elevados níveis de criticidade (fig. 5), evidenciam-se as freguesias dos concelhos de Coimbra e Almeida. O terceiro factor desempenha um papel relevante em freguesias de urbanização mais antiga localizadas, por exemplo, no centro da cidade de Coimbra, onde se observa também uma elevada percentagem de populaçáo idosa. Os restantes municípios têm um comportamento muito mais homogéneo, baixo nos casos de Proença-a-Nova, Fundão e Nelas, médio no caso de Marinha Grande e elevados no caso de Ovar.

$\mathrm{Na}$ avaliação da capacidade de suporte à escala municipal, foram recolhidas 100 variáveis, mas apenas 44 foram incluídas no modelo. Na avaliação da capacidade de suporte foram retidos 4 factores, que explicam $73 \%$ da variância total. 
Figura 5 - Criticidade em sete municípios da Região Centro
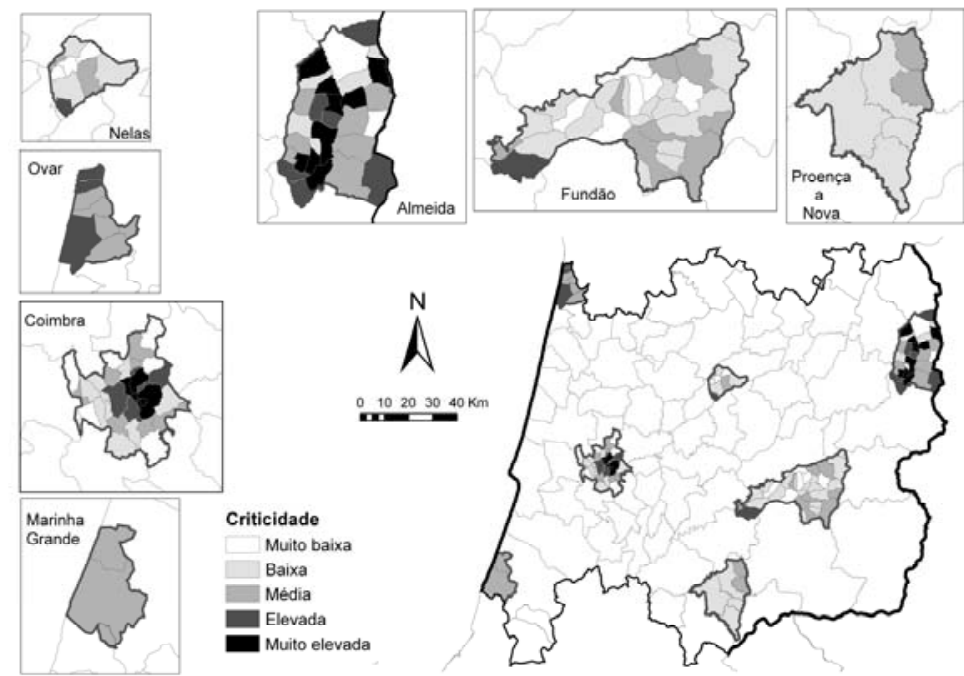

O factor 1, que explica $28.4 \%$ da variância, encontra-se relacionado com a qualidade do sistema de abastecimento de água das freguesias. O factor 2, que explica $18.6 \%$ da variância, está relacionado com os equipamentos sociais. $\mathrm{O}$ factor 3, que explica $14.5 \%$ da variância, encontra-se focado na $\mathrm{CAE}_{-} \mathrm{D}^{3}$, sobretudo quanto ao seu impacto na economia local. $\mathrm{O}$ factor 4, que explica $11.6 \%$ da variância, resume-se à variável farmácias por 1.000 habitantes.

Figura 6 - Capacidade de suporte em sete municípios da Região Centro
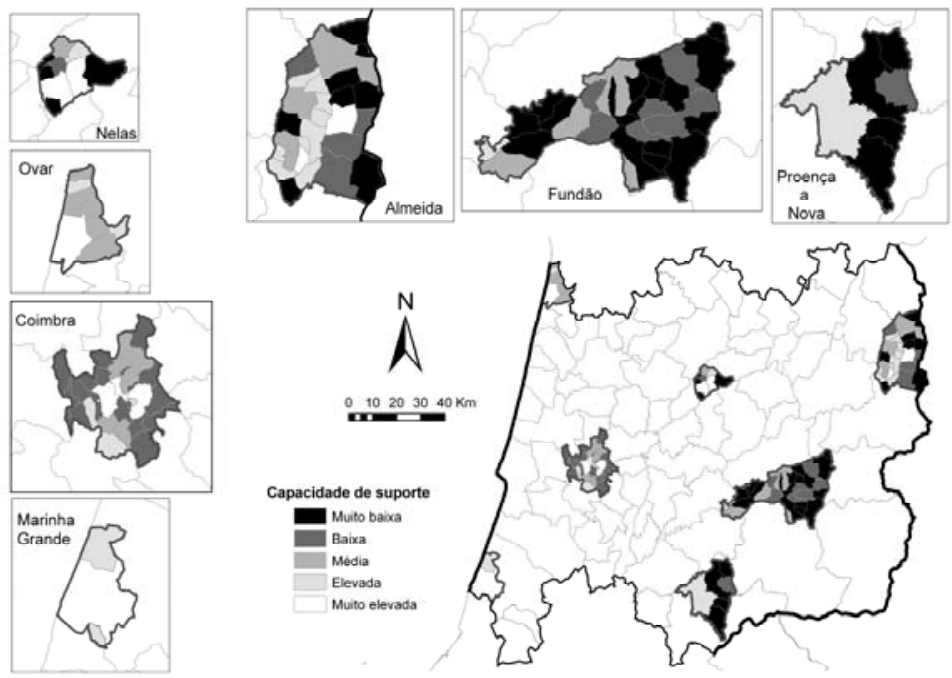

\footnotetext{
${ }^{3}$ Encontram-se incluídas na CAE - D todas as actividades relacionadas com electricidade, gás, vapor, água quente e fria e ar frio.
} 
A análise do mapa (fig. 6) mostra claramente uma maior heterogeneidade de condiçóes que no caso do mapa de criticidade. Com efeito, em todos os municípios se verifica um forte diversidade de condiçóes. De qualquer modo, os valores mais elevados em termos de capacidade de suporte estão nas freguesias dos municípios de Marinha Grande e Ovar, seguidos pelas de Coimbra, Nelas e Almeida e em posição mais desfavorável estão as dos municípios de Proença-a-Nova e Fundão.

Análise da Vulnerabilidade Social à escala municipal

A análise do mapa da fig. 7, resultante do cruzamento dos dois anteriores, continua a evidenciar, quer a diferenciação dos municípios, quer a sua elevada heterogeneidade interna. Os municípios que aparecem em posição mais favorável são os de Marinha Grande, Ovar, Coimbra e Nelas. No que diz respeito à diferenciaçáo interna sublinhe-se que os municípios do litoral apresentam uma maior homogeneidade interna e o município de Almeida é aquele em que maior número de freguesias apresenta uma elevada vulnerabilidade social, bem como o que parece deter a maior heterogeneidade de condiçóes.

Figura 7 - Vulnerabilidade social em sete municípios da Região Centro
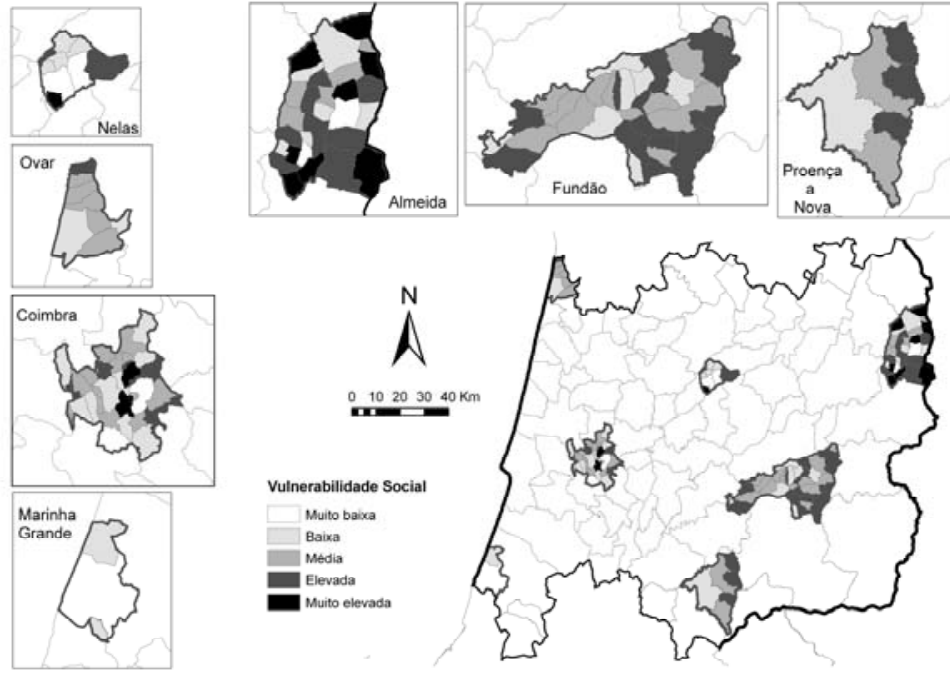

\section{CONCLUSÃO}

Os modelos de análise factorial utilizados permitiram avaliar e cruzar as características das populaçóes e das comunidades (criticidade) com as condiçóes decorrentes das infraestruturas territoriais (capacidade de suporte) para dar resposta a acontecimentos potencialmente perigosos.

Neste trabalho, a vulnerabilidade social foi avaliada a duas escalas distintas e parece importante assinalar que os métodos estatísticos utilizados determinam importâncias distintas 
para as diferentes variáveis e mesmo a utilização de variáveis completamente distintas, conforme estamos a trabalhar à escala nacional ou à escala municipal. Assim, apesar de se notar uma convergência significativa na posição relativa dos municípios da Região Centro analisados nos dois níveis escalares, realça-se que as duas componentes da vulnerabilidade social (criticidade e capacidade de suporte) náo apresentam, em regra uma correlação entre si, nem a nível da freguesia, nem a nível do concelho.

Seja como for, parece-nos que os resultados do modelo utilizado reflectem as diferentes estratégias públicas adoptadas pelos municípios em análise e permitem a definição de estratégias de mitigação do risco e de medidas de protecção civil, tendo em atenção a especificidade de cada caso. Em síntese, a cartografia da vulnerabilidade social, integrando tanto a criticidade como a capacidade de suporte, permite uma análise comparativa entre diferentes territórios, o que facilita uma melhor gestão dos recursos e infra-estruturas disponíveis e uma melhor definição das políticas públicas de sensibilização, prevenção, redução e mitigação dos riscos. Daí a necessidade de integrar a avaliação da vulnerabilidade social no processo de decisão em termos de risco e emergência.

Num cenário ideal de articulação de escalas, compatibilizando recursos e definindo níveis de intervenção prioritários, parece-nos que a cartografia da vulnerabilidade social permitirá, a nível nacional a formulação de recomendaçôes estratégicas e estruturais, a nível municipal a definição das bases para o planeamento urbano e de emergência e a nível das freguesias a selecção das intervençóes específicas e das acções de mitigação.

Finalmente, refira-se que a avaliação da criticidade e da capacidade de suporte, apresentadas neste texto, se integram num projecto de investigaçáo mais vasto de construçáo de índices de vulnerabilidade social, em que é necessária, também, a incorporação dos conhecimentos, experiências e percepçóes quanto aos riscos e ao território em que manifestam, tanto da população em geral, como, sobretudo, dos agentes intervenientes e decisores (stakeholders).

\section{REFERÊNCIAS BIBLIOGRÁFICAS}

Cutter, S., Boruff, B, Shirley, W. (2003) - Social vulnerability to environmental hazards. Social Science Quarterly, 84, pp. 242-261.

Davis, I. (2004) - Progress in Analysis of Social Vulnerability and Capacity in Greg Bankoff (Eds) Mapping Vulnerability Disasters, Development \& People, London, Earthscan, pp. 128 - 144.

Dwyer, A., Zoppou, C. Nielson, O., Day, S., Roberts, S. (2004) QuantifYing Social Vulnerability: A methodology for identifYing those at risk to natural hazards. Geoscience Australia Record.

Eakin, H., Luers A. L. (2006) - Assessing the Vulnerability of Social - Environrnental Systems. Annu. Rev. Environ. Resour., 31, pp.365-394.

ECDGE (2008) - Assessing the potential for a comprehensive community strategy for the prevention of natural and manmade disasters. Final Report. European Commission DG Environrnent, COWI.

Hufschmidt, G., Crozier, M., Glade, T. (2005) - Evolution ofNatural Risk: Research Framework and Perspectives. Natural Hazards and Earth System Sciences, 5, pp. 375-387.

Mendes, J. M.; Tavares, A. (2008) - Building resilience to natural hazards. Practices and policies on govemance and mitigation in the central region of Portugal. Safety, Reliability and Risk Analysis: Theory, Methods and Applications. Ed. Martorell et aI. Taylor and Francis Group, pp. 1577-1584.

Mendes, J.M. (2009) - Social vulnerability indexes as planning toaIs: beyond the preparedness paradigm. Journal ofRisk Research, 12: 1, pp. 43-58.

Mendes, J. M., Tavares, A., Cunha, L. e Freiria, S. (2009) - Vulnerabilidade Social aos riscos naturais e tecnológicos em Portugal. in C. Guedes Soares, C. Jacinto, A. P. Teixeira and P. Antão (org.), Riscos Industriais e Emergentes, Volume 1, Lisboa, Ediçôes Salamandra, 67-84. 
Pelling, M. (2003) - The vulnerability of cities: Natural Disasters and Social Resilience. London, Earthscan.

Prescott-Allen, R. (2001) - The Wellbeing ofNations: a Country-by-Country Index ofQuality ofLife and the Environment, Island Press.

Ribeiro, M.J. (1995) - Sociologia dos desastres, Sociologia, Problemas e Práticas 18:pp. 23-43. Lisboa, Centro de Inv. e Est. de Sociologia - ISCTE.

Schmidtlein, M. Deutsch, R. Piegorsch, W. Cutter, Susan (2008) - A sensitivity analysis of the social vulnerability index. Risk Analysis, Vo1.28, n.o4, pp. 1099-1114.

United Nations Intemational Strategy for Disaster Reduction (UN-ISDR) (2009) - Global Assessment Report on Disaster Risk Reduction. Risk and poverty in a changing climate. Geneva, Switzerland.

United Nations Organization (2004) - Living with Risk. A Global Review of Disaster Reduction Initiatives. http://www.unisdr.org/eng/aboutj.sdrlbd-Iwr- 2004-eng.htm Accessed on 1 March 2009

Wisner, B., Blaikie, P., Cannon, T., and Davis, I. (2004) - At Risk - Natural hazards, people 's vulnerability and disasters. Routledge, London, 471p. 